\title{
Determinantes da Estabilização de Preços em Ofertas Públicas Iniciais de Ações
}

\author{
Antonio Gledson de Carvalho* \\ Douglas Beserra Pinheiro***
}

\section{Resumo}

O processo clássico de estabilização de preços em IPOs consiste na venda de um lote suplementar de ações (sobrealocação) e eventualmente recompra das mesmas (aftermarket short covering ou $A S C$ ) para evitar queda acentuada ou alta volatilidade do preço. Este artigo provê uma descrição da atividade de estabilização no Brasil e investiga seus determinantes em três aspectos: o exercício da opção de sobrealocação, a ocorrência da estabilização $(A S C)$ e a intensidade da mesma. Os três diferentes aspectos da estabilização apresentam determinantes distintos: o exercício da opção de sobrealocação é determinada exclusivamente pelas condições de demanda; os IPOs estabilizados são aqueles com maior risco, com menor demanda e que são conduzidos por underwriters de melhor reputação e a intensidade da estabilização depende positivamente do risco e da demanda. Nenhum dos modelos teóricos existentes explica completamente estes resultados.

Palavras-chave: IPO; estabilização de preços; greenshoe.

Códigos JEL: G24.

\begin{abstract}
In the most common mechanism for price stabilization in IPOs, the underwriter distributes stocks in excess of what was contracted (overallotment) and eventually covers this short naked position by purchasing stocks in the secondary market (Aftermarket short covering, $A S C$ ). This mechanism can be used to avoid price drop or price volatility. This article provides a description of such activity in Brazil. We investigate the determinants of price stabilization in three aspects: amount overallotted, occurrence of ASC and its intensity. The three different aspects of price stabilization have different determinants. The amount overallotted depends only on the ex-ante demand conditions. ASC occurs mostly on IPOs characterized by high risk, low ex-ante demand and carried by reputable underwriters. The intensity of the $A S C$ increases with the riskiness and decreases with the ex-ante demand. None of the existing models fully explain these results.
\end{abstract}

Keywords: IPO; price stabilization; aftermarket short covering; greenshoe.

Submetido em janeiro de 2010. Aceito em julho de 2010. O artigo foi avaliado segundo o processo de duplo anonimato além de ser avaliado pelo editor. Editor responsável: Jairo Procianoy. Os autores são gratos a Alkimar Moura, Marco Antonio Bonomo, Rodrigo Delosso Bueno, William Eid Jr. e dois pareceristas anônimos pelos valorosos comentários. Agradecemos a Humberto Gabrielli, Humberto Gallucci Netto, Joelson Sampaio e Rodrigo Tolentino pelo excelente trabalho de assistência de pesquisa. Pinheiro agradece ao apoio financeiro da CAPES e GV-Pesquisa. Erros e omissões são de nossa inteira responsabilidade.

*FGV-EAESP, São Paulo, Brasil. E-mail: gledson.carvalho@fgv.br

**Banco Itaú Unibanco, São Paulo, Brasil. E-mail: douglas.pinheiro@itau-unibanco.com.br 


\section{Introdução}

Wilhelm Jr. (1999) lista três mecanismos usados para estabilização de preços no processo de abertura de capital (IPO do inglês initial public offering) nos Estados Unidos: 1) ordem de estabilização: uma ordem de compra colocada pelo underwriter a um preço próximo ao preço de distribuição e propriamente identificada como uma oferta de estabilização; ${ }^{1}$ 2) imposição de penalidades aos underwriters envolvidos no IPO cujos clientes vendem suas ações logo após a distribuição (flippers) ${ }^{2}$ e 3) a recompra de ações pelo underwriter (ASC do inglês aftermarket short covering). O mecanismo de estabilização mais frequentemente empregadoé o ASC (Aggarwal, 2000). No ASC, o underwriter inicialmente assume uma posição descoberta ao distribuir uma quantidade de ações maior que aquela contratada pelo emissor (denominada sobrealocação). A sobrealocação pode ser coberta de três maneiras: pela compra de um lote adicional de ações junto ao emissor ao preço de emissão (exercício da opção greenshoe); pela compra no mercado secundário das ações alocadas em excesso (ASC) ou uma combinação das duas anteriores.

Há muito o ASC é reconhecido como um fator importante em IPOs. Schultz e Zaman (1994) evidenciam o esforço dos underwriters para estabilizar preços em IPOs superavaliados. Ruud (1993) explica por que altos retornos iniciais são frequentes, ${ }^{3}$ enquanto baixos retornos são raros: os underwriters normalmente procuram estabilizar o preço a um nível próximo ao de emissão. Essa autora estima que o $A S C$ é responsável por 77\% dos retornos iniciais (underpricing) observado. Aggarwal (2000) também constata uma relação entre o ASC e underpricing.

Apesar da reconhecida importância do $A S C$, a literatura sobre o tema é ainda fragmentada: diferentes modelos teóricos propõem explicações sobre por que e quando os IPOs são estabilizados. No entanto, as evidências empíricas são insuficientes para validar qualquer dos modelos. Isso em grande medida se deve à pouca disponibilidade de dados: na maioria dos países os underwriters não são obrigados a revelar informações sobre o montante da sobrealocação ou do ASC. Como consequência, a maioria dos estudos empíricos não se baseia na sobrealocação e no $A S C$ de fato realizados, mas em estimativas da ocorrência de estabilização e da sua intensidade. Além do mais, como geralmente só é possível estimar uma variável (ou a sobrealocação ou o $A S C$ ), os modelos empíricos não supõem um processo em dois períodos, em que no primeiro é determinado o montante sobrealocado e, no segundo, o montante do ASC. Alguns exemplos de como a estabilização é estimada são: Benveniste et alii (1998) usam um algoritmo para estimar quando uma transação foi iniciada pelo comprador ou vendedor. Transações que foram iniciadas pelo comprador são identificadas como operações de estabilização. A intensidade da estabilização é medida pelo número de dias durante a primeira semana

\footnotetext{
${ }^{1}$ Este mecanismo não existe no Brasil.

${ }^{2}$ Não há informação disponível sobre o uso desse mecanismo no Brasil.

${ }^{3}$ No Brasil entre 2004 e 2007, por exemplo, os IPOs da Bovespa Holding, Gafisa e GVT apresentaram altas respectivas de 52\%, 29\% e 27\%, ao passo que apenas a Agrenco e da JBS, com perdas respectivas de $14,2 \%$ e $12 \%$, caíram mais que $10 \%$ no fechamento do primeiro dia de negociações.
} 
de negociações em que o IPO foi estabilizado; Lewellen (2006) usa a variação no estoque de ações mantido pelos market-makers que precede uma revisão para baixo no preço de compra e a frequência com que a ação é negociada ao preço de emissão durante a primeira semana após o IPO e Hanley et alii (1993) usam como indicador de estabilização o número de transações durante o primeiro dia que são feitas ao preço de emissão. Pelo nosso conhecimento, Aggarwal (2000) é o único estudo com informação sobre a estabilização de fato realizada. No entanto, esse estudo não examina os determinantes da estabilização.

No Brasil, a Comissão de Valores Imobiliários (CVM) desde 2003 determina que o coordenador da emissão publique ao término do período de estabilização uma nota contendo informações sobre ${ }^{4}$ ) como as ações fora distribuídas entre os diferentes grupos de investidores; 2) o montante sobrealocado; 3) o número de ações recompradas no ASC e 4) o montante do greenshoe que foi exercido. Esta peculiaridade institucional brasileira, i.e., disponibilidade de informação sobre o processo de estabilização, torna possível o estudo empírico da estabilização como um processo sequencial. Além do mais, a disponibilidade de informação sobre o número de investidores participantes da emissão e sobre como as ações foram distribuídas entre os diferentes grupos de investidores permite uma melhor estimação da influência da demanda ex-ante sobre a estabilização.

Este artigo documenta a atividade de estabilização de preços em IPOs no Brasil e investiga os seus determinantes em três aspectos: montante sobrealocado; ocorrência do $A S C$ e sua intensidade. Nossos dados mostram que a estabilização de preços é um aspecto importante da abertura de capital no Brasil: quase todos os IPOs preveem a estabilização de preço (apenas 2 IPOs não o fizeram). A sobrealocação média é de 13,9\% em relação à oferta inicial. Em apenas 17 IPOs, a sobrealocação foi menor do que $15 \%$ e em somente 2 casos não houve sobrealocação. O ASC foi praticado em 53 IPOs (55,2\% dos 96 IPOs com sobrealocação). Em média 34,4\% da sobrealocação (4,7\% do montante ofertado) foram recomprados. A nossa análise econométrica indica que 1) a demanda é o único fator relevante para explicar o montante sobrealocado; 2) os IPOs estabilizados são aqueles com maior risco inicial de preço (menor volume e maior intervalo de preço), menor demanda de investidores institucionais e que são conduzidos por underwriters de melhor reputação; 3 ) a intensidade da estabilização depende positivamente do risco (menor preço de emissão) e da demanda ex-ante de investidores estrangeiros. Estes resultados não são completamente previstos por nenhum dos modelos teóricos existentes.

Este artigo está organizado da seguinte forma. A Seção 2 detalha o processo de estabilização explorando as diferenças institucionais entre Brasil e Estados Unidos. A Seção 3 explora e avalia a literatura sobre determinantes da estabilização. A Seção 4 descreve as variáveis e os dados. A Seção 5 apresenta as hipóteses a serem testadas e a metodologia utilizada. A Seção 6 apresenta os resultados. Finalmente, a Seção 7 conclui este artigo.

\footnotetext{
${ }^{4}$ Instrução CVM No 400 de 29 de dezembro de 2003.
} 


\section{O Processo de Estabilização}

Este artigo tem seu foco nos determinantes do $A S C$, o mecanismo mais frequentemente utilizado ${ }^{5}$ para estabilização de preços em IPOs. O ASC funciona da seguinte maneira: no momento da distribuição do IPO, o underwriter assume uma posição descoberta ao exercer a opção de vender um número de ações maior do que o contratado com a empresa emissora. Isto é feito por meio de um empréstimo de ações junto ao emissor. ${ }^{6}$ Esta posição descoberta é denominada sobrealocação (overallotment). A opção de sobrealocar é contratada entre o underwriter e o emissor e deve constar do prospecto da emissão. Nem todos os IPOs preveem a possibilidade de sobrealocação. Nestes casos, o underwriter não tem como recomprar ações após a distribuição das mesmas.

A posição descoberta do underwriter criada com a sobrealocação pode ser coberta de três formas: 1) exercício da opção greenshoe que dá ao underwriter o direito de comprar um lote adicional de ações junto ao emissor ao preço de distribuição. O montante da opção greenshoe também deve constar no prospecto. Tanto nos EUA ${ }^{7}$ quanto no Brasil ${ }^{8}$ as normas limitam tal montante a $15 \%$ da emissão; 2) recompra de ações no mercado secundário ao preço de mercado ou 3) uma combinação dos dois mecanismos. No Brasil o valor da sobrealocação não pode exceder o montante do greenshoe. Nos EUA não existe limite para a sobrealocação e, frequentemente, esta é maior do que o greenshoe (Edwards e Hanley, 2007). No Brasil o prazo para o exercício do ASC e do greenshoe é de 30 dias. ${ }^{9}$ Nos EUA, apesar de não haver restrições legais, o greenshoe é exercido em até 30 dias (Muscarella et alii, 1992).

Alguns IPOs preveem a opção hot-issue. Esta opção dá ao underwriter e ao emissor, desde que de comum acordo, o direito de aumentar o montante da oferta no momento da distribuição das ações. Estas ações adicionais não constituem uma posição descoberta e, diferentemente da sobrealocação, não são passíveis de recompra no mercado secundário. A opção de hot-issue deve ser prevista no prospecto e no Brasil está limitada a $20 \%$ do montante inicialmente estabelecido. ${ }^{10}$

${ }^{5}$ No Brasil não existe a ordem de estabilização e desconhecemos informação quanto o uso de penalidades a underwriters que distribuem ações para flippers.

${ }^{6}$ Conforme a instrução CVM 441 de 10 de novembro de 2006.

${ }^{7} \mathrm{O}$ limite de $15 \%$ está vigente desde Agosto de 1983 nos Estados Unidos (Muscarella et alii, 1992). Antes disso o limite era de 10\% (Muscarella et alii, 1992). Chung et alii (2000) reportam que, nos Estados Unidos no período de 1984 a 1993, 92\% das emissões possuíam cláusula de greenshoe.

${ }^{8}$ A Instrução CVM No 400 de 29 de dezembro de 2003 regulamenta a emissão de ações, o processo de estabilização de preços e a divulgação de informações sobre os processos de emissão de ações.

${ }^{9}$ Apesar deste prazo não ser regulamentado, ele deve constar no prospecto. Em todas as emissões da amostra o prazo foi de 30 dias.

${ }^{10}$ Instrução CVM No 400 de 29 de dezembro de 2003. 
Assim, anteriormente ao início do processo de bookbuilding, o underwriter e o emissor devem decidir o limite para as opções de sobrealocação, greenshoe e hot-issue. Finalizado o bookbuilding, o underwriter deve decidir o preço de distribuição e a qual nível exercer as opções de hot-issue e sobrealocação. Uma vez iniciadas as negociações no mercado secundário, o underwriter deve decidir como cobrir a sobrealocação.

O underwriter não assume riscos significantes quando a sobrealocação é menor do que o greenshoe: se o preço no mercado secundário estiver acima daquele de distribuição, exerce o greenshoe para cobrir a sobrealocação. Se o preço estiver abaixo, irá recomprar as ações um preço menor do que o preço ao qual as ações foram inicialmente distribuídas. A única possibilidade de o underwriter incorrer em perda financeira é quando a sobrealocação é maior do que o greenshoe, podendo eventualmente levar o underwriter a ter que recomprar ações a um preço maior do que aquele ao qual as mesmas foram distribuídas.

Os processos de abertura de capital e estabilização realizados no Brasil são em muitos aspectos semelhantes àqueles realizados nos EUA. No entanto, existem algumas diferenças: 1) algumas regras que nos EUA são determinadas por meio de auto-regulação, no Brasil são determinadas oficialmente por meio de instruções da CVM; 2) no Brasil não existe o mecanismo de estabilização via ordem de estabilização; 3) no Brasil a posição inicial a descoberto assumida pelo underwriter não pode ser superior à opção greenshoe contratada com o emissor.

No que tange este artigo, a principal diferença entre os processos de estabilização nos EUA e Brasil é que neste último existe obrigatoriedade da divulgação $e x$ post de informações sobre a atividade de estabilização: após o término do período de estabilização, o underwriter deve publicar uma nota (denominada anúncio de encerramento de distribuição) divulgando: 1) o montante da sobrealocação; 2) se houve $A S C$; 3) quanto da sobrealocação foi coberta por meio de recompras no mercado secundário e quanto se deu por meio do exercício do greenshoe; 4) quanto da oferta total (oferta inicial acrescida da sobrealocação e hot-issue) foi alocada a cada um dos grupos de investidores (em especial, investidores estrangeiros qualificados e investidores institucionais nacionais).

\section{Racionalidade e Determinantes da Estabilização}

Na literatura encontramos apenas quatro modelos formais para explicar o ASC. Benveniste et alii (1996) adaptam o modelo de Benveniste e Spindt (1989) de modo que a estabilização de preços aparece como uma compensação dada aos investidores informados pela revelação da informação que estes fazem durante o processo de bookbuilding. Como em Benveniste e Spindt (1989) os investidores informados não têm incentivos para revelar seu interesse quando este é alto porque isso levaria o underwriter a aumentar o preço de distribuição, eliminando assim o valor da informação privilegiada. Para viabilizar a revelação da informação, os underwriters compensam os investidores informados com uma alocação maior em IPOs que são subavaliados. Em Benveniste et alii (1996), a estabilização consiste 
em mecanismo alternativo para compensar os investidores informados: recompra de ações quando estas foram superavaliadas. Desse modo, o underpricing e a estabilização são mecanismos substitutos, uma vez que a recompra de ações reduz a necessidade de underpricing. Tanto o underpricing quanto a estabilização de preços decorrem da assimetria informacional. Neste modelo, a estabilização não é descrita como um processo onde as decisões de sobrealocação e recompra ocorrem em sequência: somente a recompra é modelada.

Chowdhry e Nanda (1996) baseiam-se no modelo de Rock (1986) para explicar a estabilização de preços: os investidores não-informados têm maior probabilidade de receber ações em um IPO quando este é superavaliado. Os underwriters podem compensar os investidores não-informados subavaliando as emissões ou recomprando parte das ações quando essas foram superavaliadas. Assim, a estabilização funciona como uma opção de venda dada aos investidores desinformados. As previsões empíricas são similares às de Benveniste et alii (1996): estabilização de preços está associada a informação assimétrica. Também neste modelo, estabilização é confundida com recompra de ações: a sobrealocação não é modelada.

Prabhala e Puri (1998) modelam a sobrealocação como uma opção que os underwriters dão aos investidores de devolverem uma parte das ações distribuídas. Desse modo a sobrealocação representa para o underwriter uma posição descoberta em uma opção de venda. Portanto, o custo da estabilização cresce com o risco e, por isso, IPOs com menor risco ex-ante são mais frequentemente estabilizados. Deve-se notar que esta conclusão é oposta à Chowdhry e Nanda (1996) e Benveniste et alii (1998) em que a estabilização aparece como substituto ao underpricing e, portanto, deveria ocorrer em IPOs de maior risco.

Finalmente, Zhang (2004) usa o arcabouço de Benveniste e Spindt (1989) para explicar por que a sobrealocação é mais intensa quando a demanda é baixa. ${ }^{11}$ Nesse modelo, a utilidade do underwriter tem dois componentes: o underpricing que reduz a sua comissão e a estabilização que representa um compromisso de recomprar ações a um preço maior que o de emissão. Este autor argumenta que a sobrealocação afeta positivamente o preço no mercado secundário por vários motivos: 1) investidores que já possuem o ativo são mais propensos a mantê-lo do que aqueles que ainda o comprarão; 2) o uso de penalidades contra os flippers, ${ }^{12}$ bem como contra os membros do consórcio que vendem para os mesmos, fornece incentivos para que estes investidores mantenham o ativo em seus estoques; 3) a sobrealocação favorece o atendimento dos clientes institucionais, que exigem uma participação mínima no IPO e 4) a sobrealocação permite que o underwriter aumente a sua base de clientes e, assim, melhore a liquidez e reduza o risco do ativo para os investidores. Desse modo, ao fixar o nível de sobrealocação, o underwriter

\footnotetext{
${ }^{11}$ Zhang (2004) procura explicar a evidência reportada em Aggarwal (2000) segundo a qual os underwriters sobrealocam mais intensamente quando o preço de emissão é fixado a um nível inferior à média do intervalo de preço fixado no prospecto. A fixação de um preço inferior ao preço médio é vista como um indício de baixa demanda.

${ }^{12}$ Investidores que vendem a sua alocação do IPO nos primeiros dias de negociação para realizar ganho.
} 
faz um balanço entre o custo de ter que recomprar as ações sobrealocadas a um preço maior que o de emissão e o aumento da comissão ocorre por conta do aumento de preço que decorre da sobrealocação. Quanto menor a demanda, maior o segundo componente e, consequentemente, maior a sobrealocação. O ASC não é explicitamente modelado.

Além dos modelos formais acima descritos, alguns outros autores apresentam de maneira informal outras razões para a estabilização de preços: 1) Hanley et alii (1993) sugerem que porque a reversão do preço pode ser acompanhada de movimentos de mercado e choques de informações, a manutenção temporária de um preço artificialmente alto por meio da estabilização permite aos underwriters despistar os investidores quando o IPO foi superavaliado; 2) Schultz e Zaman (1994) argumentam que a estabilização aumenta permanentemente o preço no mercado secundário: devido a eventuais atrasos na liquidação, os investidores eventualmente podem cancelar suas ordens de compra do IPO nos primeiros dias de negociação. Eles assim procedem quando o IPO é superavaliado, uma vez que podem comprar a mesma ação no mercado secundário a um preço menor. Para evitar que isso ocorra, o underwriter se compromete a recomprar ações no mercado secundário a um preço próximo ao de distribuição e 3) Lewellen (2006) argumenta que os underwriters fazem estabilização de preços para proteger sua reputação: os investidores inferem a habilidade, esforço e honestidade do underwriter examinando o desempenho passado do mesmo. Os underwriters se deparam com incerteza na hora de apreçar um IPO. Mesmo underwriters competentes e honestos podem errar ao avaliar o preço do IPO. Um erro pode ser facilmente confundido com incompetência, negligência ou má-intenção. A estabilização de preços, por minorar o dano causado aos investidores, protege a reputação do underwriter.

Assim como a literatura teórica, a literatura empírica sobre estabilização também é breve, especialmente no que se refere aos seus determinantes. A estabilização em IPOs tem sido com mais frequência estudada nos Estados Unidos. ${ }^{13}$ No entanto, devido à indisponibilidade de informação, a ocorrência de estabilização é presumida, i.e., alguma metodologia é usada para prever quando a estabilização ocorreu. A notória exceção é Aggarwal (2000) que dispõe de informações precisas sobre a estabilização, para uma pequena amostra de IPOs. Essa autora analisa o uso dos diversos mecanismos de estabilização, mas não investiga os seus determinantes. É importante destacar que os dados usados por Aggarwal não foram e não são de domínio público.

\footnotetext{
${ }^{13}$ São poucos os países onde existe um mercado ativo para IPOs e onde informações sobre o processo de estabilização sejam de domínio público.
} 
Hanley et alii (1993) analisam 1523 IPOs realizados nos Estados Unidos no período entre 1982 e 1987. Nessa análise a estabilização é presumida pela proximidade do preço de negociação ao preço de emissão e pelo preço teórico da opção de venda da ação. Esses autores constataram que o bid-ask spread ${ }^{14}$ é menor para os IPOs estabilizados e que há ocorrência de uma queda de preço das ações após o fim da estabilização.

Benveniste et alii (1998) usando uma amostra de 552 IPOs realizados entre 1993 e 1994 nos Estados Unidos, confirmando Benveniste et alii (1996) e contrariando Chowdhry e Nanda (1996), verificam que os investidores institucionais são os maiores beneficiários do processo de estabilização. Esse artigo também estuda os determinantes da intensidade de estabilização. A intensidade é medida pelo número de dias durante os quais o IPO foi estabilizado. Esses autores verificam que quanto maior a posição inicial descoberta e a revisão positiva do preço em relação ao intervalo de preço informado no prospecto, menor a intensidade da estabilização. É importante ressaltar que estas últimas variáveis são associadas à demanda pelo $I P O$. A relação negativa entre demanda e estabilização não é prevista por nenhum dos modelos teóricos sobre estabilização. A metodologia usada para detecção da atividade de estabilização parte dos microdados das operações de compra e venda e baseia-se fundamentalmente na categorização da operação como iniciada pelo comprador ou vendedor do ativo. ${ }^{15}$ Supõe-se que operações iniciadas pelos compradores são ordens de estabilização.

Prabhala e Puri (1998) usaram três amostras. Uma de IPOs que ocorreram entre 1981 e 1982. Nessa amostra, tinham informação de que a estabilização ocorreu em 46 IPOs. Para os demais 162 IPOs houve a presunção de que não houve estabilização. A outra amostra consiste de 2723 IPOs entre 1985 e 1994 com estabilização presumida pelo comportamento dos preços no mercado secundário e a comparação das estabilizações realizadas antes e após $1934 .{ }^{16}$ Estes autores constatam que IPOs que possuem menor risco inicial de preços são mais frequentemente estabilizados.

\footnotetext{
${ }^{14}$ Diferença entre o maior preço de oferta de compra e a menor oferta de venda do ativo em dado momento.

${ }^{15}$ A operação é classificada de acordo com o algoritmo desenvolvido por Lee e Ready (1991).

${ }^{16}$ Ano em que a SEC Norte-Americana definiu uma regulamentação mais restritiva para a realização da estabilização.
} 
Lewellen (2006) analisa a intensidade da estabilização. Como não dispõe de informações precisas sobre ocorrência e intensidade da estabilização, usa três proxies diferentes para a intensidade da estabilização: variação no estoque de ações detidas pelos market-makers, variação no estoque dos market-makers que precede uma revisão para baixo nas ordens de compra destes e frequência de negociações que ocorrem no primeiro dia de negociação ao preço de oferta. Usando uma amostra de 1422 IPOs realizados na Nasdaq entre 1996 e 1999, a autora conclui que a intensidade da estabilização é 1) positivamente correlacionada com a reputação do underwriter; 2) positivamente correlacionada com a participação do varejo na alocação inicial, i.e., underwriters com maior volume de operação no varejo estabilizam mais intensamente; e 3) aparentemente não correlacionada com o risco.

Finalmente, em um estudo de caso, Boehmer e Fishe (2004) encontram evidências para a suposição de que a estabilização acarreta ganhos financeiros para o underwriter e também para a importância desse processo na provisão de liquidez e sustentação do preço no mercado secundário.

\section{Variáveis e Dados}

\subsection{Variáveis}

As variáveis que caracterizam o processo de estabilização são Sobrealocação: uma variável binária que assume valor um quando a sobrealocação foi exercida ao valor máximo estabelecido no prospecto e zero, do contrário ${ }^{17}$ Estabilização: uma variável binária que indica a ocorrência de recompras no mercado secundário pelo underwriter; Intensidade-da-estabilização: parte da sobrealocação coberta por meio do ASC. Se nenhuma ação foi recomprada durante o período de estabilização, ou se todas as ações recompradas foram posteriormente revendidas a Intensidade-da-estabilização assume valor zero. Caso toda a sobrealocação tenha sido coberta por recompras no mercado secundário, assume valor um. A Tabela 1 descreve detalhadamente todas as variáveis usadas neste artigo.

\footnotetext{
${ }^{17}$ Em nossa amostra, em apenas 17 IPOs a sobrealocação não foi exercida no seu nível máximo de $15 \%$, de modo que há pouca variação longitudinal. Por essa razão, tornou-se mais conveniente definir uma variável binária.
} 
Tabela 1

Descrição das variáveis

\begin{tabular}{|c|c|}
\hline Variável & Descrição \\
\hline Sobrealocação & $\begin{array}{l}\text { Variável binária que assume valor um quando a sobrealocação } \\
\text { foi exercida ao valor máximo estabelecido no prospecto e zero, } \\
\text { do contrário. }\end{array}$ \\
\hline Estabilização & $\begin{array}{l}\text { Variável binária que indica a ocorrência de estabilização. As- } \\
\text { sume valor um quando o underwriter recomprou ações no mer- } \\
\text { cado secundário e zero do contrário. }\end{array}$ \\
\hline Intensidade da Estabilização & $\begin{array}{l}\text { Proporção da sobrealocação que foi coberta por meio de re- } \\
\text { compras no mercado secundário. Calculada pela seguinte } \\
\text { fórmula: } \\
\text { intensidade de estabilização }=\frac{\text { sobrealocação - greenshoe }}{\text { sobrealocação }}\end{array}$ \\
\hline Tamanho & $\begin{array}{l}\text { Tamanho da oferta medido pelo logaritmo natural do valor da } \\
\text { oferta medido em reais, descontadas as ações suplementares } \\
\text { decorrentes das opções de hot-issue ou de sobrealocação. Este } \\
\text { difere do valor de oferta informado na Tabela } 3 \text {, pois aquele se } \\
\text { refere ao valor final. }\end{array}$ \\
\hline Comissão & $\begin{array}{l}\text { Comissão do underwriter calculada como a diferença entre o } \\
\text { preço de emissão e o valor pago pelo Underwriter ao emissor, } \\
\text { dividido pelo preço de emissão. }\end{array}$ \\
\hline Underwriter & $\begin{array}{l}\text { Reputação do underwriter de acordo com a escala desen- } \\
\text { volvida por Carter e Manaster (1990) e atualizado por Jay Rit- } \\
\text { ter para o período de 2001-2004. O valor utilizado é aquele as- } \\
\text { sociado ao participante do consórcio com melhor classificação } \\
\text { (instituições subcontratadas não foram consideradas). Emis- } \\
\text { sores sem classificação receberam a menor pontuação da es- } \\
\text { cala que é 1.1. }\end{array}$ \\
\hline Preço & Preço de emissão \\
\hline Intervalo de Preço & $\begin{array}{l}\text { Diferença entre o preço máximo e mínimo da faixa inicial in- } \\
\text { formada no prospecto preliminar dividido pelo preço médio. }\end{array}$ \\
\hline Número de investidores & $\begin{array}{l}\text { Número de investidores que receberam alocação no IPO. } \\
\text { Investidores institucionais nacionais são especificados nos } \\
\text { anúncios de encerramento como fundos de investimento, fun- } \\
\text { dos de previdência privada, companhias seguradoras, demais } \\
\text { instituições financeiras e outros.* Os investidores interna- } \\
\text { cionais são todos qualificados. Os investidores de varejos são }^{*} \\
\text { aqueles especificados como pessoas físicas, clubes de investi- } \\
\text { mentos e demais pessoas jurídicas. }\end{array}$ \\
\hline Desvio Preço & $\begin{array}{l}\text { Calculado como a diferença entre o preço de emissão e o preço } \\
\text { médio da faixa inicial proposta no prospecto, normalizado pelo } \\
\text { preço médio da faixa inicial. }\end{array}$ \\
\hline Lote Médio & $\begin{array}{l}\text { Lote médio alocado a investidores institucionais nacionais, } \\
\text { estrangeiros e varejo, calculadas de acordo com a seguinte } \\
\text { fórmula: lote médio = } \\
\frac{\text { num. de ações adq. pelo grupo / num. de invest. no grupo }}{\text { total de ações distribuídas }}\end{array}$ \\
\hline
\end{tabular}
operações, tais como o próprio underwriter ou sócios das empresas emissoras.

As variáveis exógenas que caracterizam a oferta são Tamanho: medido pelo logaritmo natural do valor da oferta, sem incluir o hot-issue ou a sobrealocação; Comissão: comissão do underwriter calculada como a parcela em termos per- 
centuais do preço de emissão que cabe ao mesmo; Preço: preço de emissão; Intervalo-de-preço: diferença entre o preço máximo e mínimo do intervalo inicial para o preço informado no prospecto preliminar dividido pelo ponto médio do intervalo; Desvio-Preço: diferença entre o preço de emissão e o preço médio do inicial proposto no prospecto, normalizado pelo preço médio da faixa inicial; Número-de-investidores institucionais nacionais, estrangeiros e de varejo: número de investidores que receberam alocação no $I P O ;{ }^{18}$ Lote Médio: montante alocado em média a investidores institucionais nacionais, estrangeiros e do varejo e underwriter: como frequentemente se faz, usamos o grau atribuído ao underwriter participante na emissão com maior reputação segundo a escala desenvolvido por Carter e Manaster (1990) e atualizado por Jay Ritter ${ }^{19}$ para o período de 2001-2004 (underwriters que não constavam da escala receberam o menor grau: 1,1).

As variáveis Tamanho, Comissão, Preço e Intervalo-de-preço normalmente são associadas ao risco da emissão. O valor da comissão normalmente é maior para emissões de difícil apreçamento e, por essa razão, é comumente usada como proxy para risco ex-ante. Ademais, essa comissão normalmente é maior para underwriters de melhor reputação. IPOs com menor preço de oferta são mais especulativos e mais difíceis de apreçar, sendo portanto, negativamente correlacionado com o risco (Tinic, 1988). Um elevado preço de oferta também faz com que o valor mínimo de negociação no mercado secundário seja alto e isso pode inviabilizar as operações dos pequenos investidores. IPOs de alto risco em que o apreçamento é difícil devem apresentar um intervalo inicial de preços amplo.

A variável Desvio-Preço é tradicionalmente usada como controle para demanda, pois normalmente IPOs com forte demanda ex-ante (constatada durante o bookbuilding) têm o seu preço revisto para cima. No entanto, esta variável é pouco precisa como medida de demanda, pois o ajuste de preço é apenas parcial, e somente em casos extremos o preço de distribuição é fixado fora da faixa inicialmente prevista (Hanley et alii, 1993). As variáveis Número-de-investidores e Lote-médio refletem mais acuradamente a demanda ex-ante pela emissão.

Os investidores estrangeiros, em sua maioria institucionais, foram considerados separadamente dos investidores nacionais devido à sua maior capacidade em avaliar o valor dos IPOs e às fortes relações que mantêm com os underwriters, em sua maioria também estrangeiros (Ljungqvist et alii, 2003). A participação dos investidores de varejo também é interessante, uma vez que o underwriter não pode reduzir o montante alocado aos mesmos a menos de $10 \%,{ }^{20}$ diferentemente do que

\footnotetext{
${ }^{18}$ Investidores institucionais nacionais são especificados nos anúncios de encerramento como fundos de investimento, fundos de previdência privada, companhias seguradoras, demais instituições financeiras e outros. Os investidores internacionais são todos qualificados. Outros investidores institucionais nacionais (e.g., o underwriter, sócios das empresas emissoras) foram excluídos, por serem insiders nas operações. Os investidores de varejos são aqueles especificados como pessoas físicas, clubes de investimentos e demais pessoas jurídicas.

${ }^{19}$ A escala é ordinal e assume valores entre 1,1 para os underwriters de menor reputação e 9,1 para os de maior reputação. Os dados estão disponibilizados no site (http://bear.cba.ufl.edu/ ritter/ipodata.htm). O site foi acessado em 30/09/2007.

${ }^{20} \mathrm{Em}$ algumas poucas emissões, investidores de varejo classificados como flippers não foram aten-
} 
porventura ocorre com os investidores institucionais participantes do processo de bookbuilding.

\subsection{Dados}

A nossa amostra inicial consiste de todas as 106 ofertas públicas iniciais (IPOs) realizadas na Bovespa entre os anos de 2004 a 2007. Da amostra inicial, a oferta da Renar Maças foi excluída porque foi feita na base dos melhores esforços. Todas as demais emissões foram feitas no regime de garantia firme. A oferta da Gol foi excluída por não prever estabilização de preços. Outras seis emissões (Brasil Agro, MMX, Abyara, Investtur, MPX e Brasil Brokers) foram excluídas porque eram direcionadas apenas para clientes institucionais nacionais e estrangeiros (nessas ofertas o preço inicial foi fixado em valores extremamente altos de modo a excluir os investidores de varejo). Assim, a nossa amostra final é composta de 98 IPOs. Da nossa amostra, apenas 16 IPOs não ocorreram no Novo Mercado ou no Nível 2 de Governança Corporativa, no entanto, apesar de não estarem sujeitas às regras dos mercados regulados, essas emissões também previam em seus prospectos a reserva de $10 \%$ da emissão para os investidores de varejo.

Os dados referentes às ofertas foram obtidos a partir dos prospectos de distribuição de valores mobiliários e todos os outros documentos a eles relacionados, tais como os anúncios de início e encerramento da distribuição. No anúncio de encerramento são informados a sobrealocação, o detalhamento das operações de recompra e revenda de ações no mercado secundário durante o período da estabilização e a alocação inicial das ações por categorias de investidores. Estes dados estão disponíveis nos sites da CVM, CBLC e BMF-Bovespa. ${ }^{21}$ As cotações dos preços das ações e do índice Ibovespa foram obtidos da Economática ${ }^{\circledR}$.

A Tabela 2 reporta a correlação entre as variáveis que caracterizam os IPOs. Conforme o esperado pode-se constatar forte correlação negativa entre a comissão paga aos underwriters e o tamanho das ofertas, uma vez que maiores volumes garantem maiores comissões em termos absolutos, porém menores em termos relativos, face à economia de escala existente no processo (Chen e Ritter, 2000). O Tamanho apresenta correlação positiva com o Desvio-preço, indicando que maiores ofertas possuem maior demanda revelada durante o processo de bookbuilding. A mesma correlação positiva ocorre entre as variáveis Preço e Desviopreço. Pode-se observar que a correlação entre as variáveis representativas da demanda, apesar de estatisticamente significante, apenas em poucos casos supera os $60 \%$. Isso indica que estas variáveis capturam diferentes dimensões da demanda. Finalmente, as outras variáveis associadas ao risco apresentam baixa correlação entre si, bem como com as variáveis de demanda.

didos. Este instrumento passou a ser utilizado apenas em fins de 2007.

${ }^{21}$ Quais sejam: www.cvm.gov.br, www.cblc.com.br e www.bmfbovespa.com.br. 
Tabela 2

Matriz de correlação das variáveis independentes

Análise das correlações entre as variáveis independentes. As variáveis são: Tamanho: logaritmo natural do valor total do IPO desconsiderando sobrealocação e hotissue; Comissão: comissão percentual recebida pelo underwriter, Underwriter. grau attibuido do underwriter participante da oferta de maior reputação segundo a escala desenvolvida por Carter e Manaster (1990) e atualizado por Jay Ritter para o período de 2001-2004, Preço: preço de distribuição das ações, Desvio-preço: relação entre

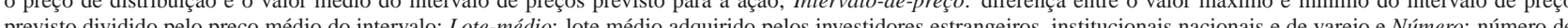
investidores estrangeiros institucionais nacionais e de varejo participantes (T) Tacionais e de varejo participantes

\begin{tabular}{|c|c|c|c|c|c|c|c|c|c|c|c|}
\hline & Tamanho & Comissãa & Underwriter & Preço & $\begin{array}{l}\text { Desvio } \\
\text { preço } \\
\text { médio }\end{array}$ & \begin{tabular}{|l|} 
intervalo \\
de preço
\end{tabular} & \begin{tabular}{|c|} 
Lote \\
médio \\
estrangeiros
\end{tabular} & \begin{tabular}{|c|c} 
Lote \\
médio \\
institucionais
\end{tabular} & \begin{tabular}{|l} 
Lote \\
médio \\
varejo
\end{tabular} & \begin{tabular}{|c|} 
Número \\
estrangeiros
\end{tabular} & \begin{tabular}{|c} 
Número \\
institucionais \\
nacionais
\end{tabular} \\
\hline Comissão & $-0,27 * * *$ & & & & & & & & & & \\
\hline Underwriter & $0,17^{*}$ & 0,03 & & & & & & & & & \\
\hline Preço & 0,12 & 0,00 & $-0,05$ & & & & & & & & \\
\hline Desvio-preço & $0,28 * * *$ & 0,07 & 0,03 & $0,40^{* * * *}$ & & & & & & & \\
\hline Intervalo-de-preço & $-0,13$ & $0,21^{* *}$ & 0,08 & $-0,31^{* * * 4}$ & $-0,05$ & & & & & & \\
\hline Lote-médio estrangeiros & $-0,32^{* * * *}$ & $-0,02$ & 0,12 & $-0,04$ & $-0,44 * * *$ & 0,01 & & & & & \\
\hline Lote-médio institucionais nacionais & $-0,16$ & 0,01 & 0,09 & $0,18^{*}$ & $-0,25 * *$ & 0,01 & $0,58^{* * *}$ & & & & \\
\hline Lote-médio varejo & $-0,26 * * *$ & $-0,05$ & 0,01 & $-0,06$ & $-0,17^{*}$ & $-0,25^{* * *}$ & $0,37^{* * * *}$ & 0,06 & & & \\
\hline Número estrangeiro & $0,70^{\text {**** }}$ & $-0,19^{* *}$ & 0,08 & $0,23 * *$ & 0,58 **** & $-0,15$ & $-0,51$ *** & $-0,25$ *** & $-0,20^{* * *}$ & & \\
\hline Número institucionais nacionais & $0,51^{* * * *}$ & $-0,13$ & $-0,04$ & $0,39 * * *$ & $0,58^{* * * *}$ & $-0,34 * * *$ & $-0,54 * * *$ & $-0,35 * * *$ & $-0,18^{*}$ & $0,67 * * *$ & \\
\hline Número varejo & $0,54^{* * * *}$ & $-0,15$ & 0,07 & 0,02 & $0,31 * * *$ & $-0,15$ & $-0,22^{* *}$ & $-0,12$ & $-0,18^{*}$ & $0,60^{* * * *}$ & 0,39 *** \\
\hline
\end{tabular}

***,**** indicam significância estatística aos níveis de $1 \%, 5 \%$ e $10 \%$ respectivamente. 


\section{Metodologia}

Este artigo analisa os determinantes dos três principais componentes do processo de estabilização: a sobrealocação, a ocorrência de $A S C$ (recompras no mercado secundário) e a intensidade do $A S C$ (proporção da sobrealocação que é coberta por meio do $A S C$ ).

Chowdhry e Nanda (1996) e Benveniste et alii (1996) argumentam que a estabilização e o underpricing são substitutos na mitigação dos problemas gerados pela assimetria de informação. Como consequência, quanto maior a assimetria de informação maior a intensidade de estabilização ou maior o underpricing. A dificuldade de testar empiricamente esta proposição reside no fato de que a assimetria de informação não é uma variável diretamente observável, no entanto, vários autores supõem que ela é correlacionada à incerteza envolvida na emissão. Assim, de acordo com o argumento de Chowdhry e Nanda (1996) e Benveniste et alii (1996), deveríamos observar uma correlação positiva entre risco e estabilização. De outro lado, Prabhala e Puri (1998) argumentam que a estabilização é tão mais custosa para o underwriter quanto maior for a incerteza do preço do IPO. Assim, Prabhala e Puri (1998) concluem que a estabilização é negativamente correlacionada com o risco. Dadas as previsões conflitantes entre Chowdhry e Nanda (1996), Benveniste et alii (1996) e Prabhala e Puri (1998), a nossa primeira hipótese pode ser formulada da seguinte maneira:

Hipótese 1. A estabilização está correlacionada (positiva ou negativamente) ao risco

Zhang (2004) relaciona estabilização a fraca demanda, ao passo que Lewellen (2006) argumenta e mostra evidências de que underwriters de maior reputação são mais ativos em estabilizar IPOs. Deste modo, as duas outras hipóteses a serem testadas são:

Hipótese 2. A estabilização é mais frequente/intensa em IPOs conduzidos por underwriters de alta reputação.

e

Hipótese 3. A estabilização é mais frequentelintensa em IPOs com baixa demanda.

O modelo econométrico usado para avaliar os determinantes da estabilização tem a seguinte forma:

$$
\text { indicador de estabilização }=\beta_{1}+\beta_{2} X+\beta_{3} Y+\beta_{4} U+\epsilon
$$

onde, $X$ é um vetor de variáveis representando o risco ex-ante, $Y$ é um vetor de variáveis representando a demanda e $U$ representa a reputação do underwriter. 
Os nossos indicadores de estabilização são Sobrealocação; Estabilização e Intensidade-da-estabilização. As variáveis Sobrealocação e Estabilização são variáveis binárias e, por consequência, serão estimadas usando o modelo Probit. A variável Intensidade-da-estabilização é limitada ao intervalo entre 0 e $100 \%$ e, portanto, será estimada pelo modelo Tobit.

As variáveis associadas ao risco são tamanho da emissão (Tamanho), comissão do underwriter (Comissão), preço de emissão (Preço) e o intervalo de preços constante no prospecto preliminar (Intervalo-de-preço). As variáveis associadas à demanda são: número de investidores participantes da emissão (Número-deinvestidores institucionais nacionais, estrangeiros e de varejo), o lote médio recebido por investidor (Lote-médio de institucionais nacionais, estrangeiros e de varejo) e o desvio do preço de emissão em relação ao preço médio do prospecto (Desvio-preço). A reputação do underwriter é representada pelo índice CarterManaster atualizado por Jay Ritter para o período de 2001-2004.

\section{Análise Empírica}

A Tabela 3 apresenta dados descritivos dos IPOs e do processo de estabilização de preços no Brasil. O volume médio captado foi de $\mathrm{R} \$ 786$ milhões por emissão. A maior emissão foi de $\mathrm{R} \$ 6,6$ bilhões e a mínima, $\mathrm{R} \$ 252$ milhões. O underpricing médio registrado no período foi de $5,6 \%$ (máximo de $52 \%$ e mínimo de -14\%). A sobrealocação média foi de 13,9\%. Em apenas 17 IPOs, a sobrealocação foi menor do que o máximo previsto $(15 \%)$ e em somente 2 casos não houve sobrealocação. A estabilização $(A S C)$ foi praticada em 53 IPOs $(55,2 \%$ dos 96 IPOs com sobrealocação). Em média, $34,4 \%$ da sobrealocação foram recomprados, o que representa na média 4,7\% do montante ofertado. Em 53 das 96 emissões com sobrealocação $(55,2 \%)$ a recompra líquida foi nula, i.e., a sobrealocação foi integralmente coberta pelo greenshoe (em 10 destes casos o underwriter chegou a recomprar ações, mas posteriormente as revendeu). Em 20 casos a sobrealocação foi integralmente coberta por recompras (o greenshoe foi zero). A média do greenshoe exercido em relação à sobrealocação foi de 65,7\% (9,3\% em relação à oferta inicialmente prevista). A opção hot-issue foi exercida em apenas 15 IPOs e em todos esses casos a sobrealocação foi a máxima prevista (15\%), sugerindo uma ordem de preferências: se a demanda comportar, primeiros se sobrealoca e apenas posteriormente se exerce a opção hot-issue. Em apenas 3 dos 15 casos em que a opção hot-issue foi exercida (20\%) houve recompra. 
Tabela 3

Descrição da atividade de estabilização

Amostra compostas por empresas que abriram capital entre 2004 e 2007. Tamanho: montante distribuído em termos nominais em milhões de reais; Hot-issue: número de ações exercidas pela opção em relação à emissão inicial; Sobrealocação: volume de ações exercidas pela opção de sobrealocação em relação à emissão inicial; Intensidade da estabilização: montante recomprado no mercado secundário durante o processo de estabilização; e Greenshoe: montante de ações adicionais adquiridas pelo underwriter junto ao emissor em relação ao número de ações oferecidas; Participação de investidores internacionais: proporção da oferta (acrescida da sobrealocação) alocada aos investidores internacionais; Participação de investidores institucionais nacionais: proporção da oferta (acrescida da sobrealocação) alocada aos investidores institucionais nacionais; Participação de investidores de varejo: proporção da oferta (acrescida da sobrealocação) alocada aos investidores de varejo; e Underprincing: retorno observado no primeiro dia de negociação em relação ao preço de distribuição

\begin{tabular}{l|c|c|c|c|c|c}
\hline & $\begin{array}{c}\text { Número } \\
\text { de IPOs }\end{array}$ & Média & Mediana & $\begin{array}{c}\text { Máximo } \\
\text { (núm. de IPOs) }\end{array}$ & $\begin{array}{c}\text { Mínimo } \\
\text { (núm. de IPOs) }\end{array}$ & Desvio-padrão \\
\hline $\begin{array}{l}\text { Montante } \\
\text { (R\$ milhões) }\end{array}$ & 98 & 768 & 541 & 6.626 & 252 & 949 \\
\hline Underpricing & 98 & $5,6 \%$ & $2,3 \%$ & $52,1 \%$ & $-14,2 \%$ & $10 \%$ \\
\hline Hot-issue & 98 & $2,3 \%$ & 0 & $\begin{array}{c}20 \% \\
(8)\end{array}$ & $\begin{array}{c}0 \\
(83)\end{array}$ & $6.0 \%$ \\
\hline $\begin{array}{l}\text { Sobrealocação } \\
\text { (em razão da emissão) }\end{array}$ & 98 & $13,9 \%$ & $15 \%$ & $\begin{array}{c}15 \% \\
(80)\end{array}$ & $\begin{array}{c}0 \\
(2)\end{array}$ & $3,3 \%$ \\
\hline $\begin{array}{l}\text { Intensidade da Estabilização } \\
\text { (em razão da sobrealocação) }\end{array}$ & 96 & $34,4 \%$ & 0 & $\begin{array}{c}100 \% \\
(20)\end{array}$ & $\begin{array}{c}0 \\
(53)\end{array}$ & $43,1 \%$ \\
\hline $\begin{array}{l}\text { Intensidade da Estabilização } \\
\text { (em razão do valor da emissão) }\end{array}$ & 98 & $4,7 \%$ & 0 & $\begin{array}{c}15 \% \\
(14)\end{array}$ & $\begin{array}{c}0 \\
(55)\end{array}$ & $6,1 \%$ \\
\hline $\begin{array}{l}\text { Greenshoe } \\
\text { (em razão da sobrealocação) }\end{array}$ & 96 & $65.7 \%$ & $100 \%$ & $\begin{array}{c}100 \\
(53)\end{array}$ & $\begin{array}{c}0 \\
(21)\end{array}$ & 43.1 \\
\hline $\begin{array}{l}\text { Greenshoe } \\
\text { (em razão do valor da emissão) }\end{array}$ & 98 & $9,2 \%$ & $15 \%$ & $\begin{array}{c}15 \% \\
(47)\end{array}$ & $\begin{array}{c}0 \\
(23)\end{array}$ & $6,6 \%$ \\
\hline $\begin{array}{l}\text { Participação de } \\
\text { investidores internacionais }\end{array}$ & 98 & $66,9 \%$ & $69,7 \%$ & $90,7 \%$ & 0 & $15,3 \%$ \\
\hline $\begin{array}{l}\text { Participação de investidores } \\
\text { institucionais nacionais }\end{array}$ & 98 & $20 \%$ & $19,9 \%$ & $58,3 \%$ & 0 & $10,76 \%$ \\
\hline $\begin{array}{l}\text { Participação de investidores } \\
\text { de varejo }\end{array}$ & 98 & $9,9 \%$ & 9,3 & 39,8 & 0,85 & 4,83 \\
\hline
\end{tabular}

No que se refere à participação dos diferentes grupos de investidores na alocação dos IPOs, a aquisição média por investidores estrangeiros foi de $69,9 \%$ das emissões; por investidores institucionais nacionais, $20 \%$ e por investidores de varejo, 9,9\%. Em apenas 22 IPOs os investidores de varejo receberam uma alocação superior a 10\% (mínimo estabelecido para o Novo Mercado e para o Nível 2 de Governança Corporativa), sendo que em apenas 5 casos a participação do varejo foi superior a $15 \%$ e em 12 , inferior a $7 \%$.

A Tabela 4 divide os IPOs entre estabilizados e não-estabilizados de modo a permitir uma comparação entre os processos de estabilização no Brasil e nos Estados Unidos (conforme dados reportados em Aggarwal (2000)). Pode-se observar que o valor médio das emissões no Brasil é maior que nos EUA: US\$ $384 \mathrm{mi}$ contra US\$ 96 mi. O valor da emissão dos IPOs não-estabilizados é em média maior que o dos não-estabilizados: US\$ $512 \mathrm{mi}$ contra US\$ 275 no Brasil e US\$ 113 contra US\$ 82 nos EUA. O underpricing médio é maior em IPOs não estabilizados: $4,0 \%$ contra $12,6 \%$ no Brasil e 9,3\% contra $24,2 \%$ nos EUA. O underpricing médio no Brasil é consideravelmente menor que nos EUA: 5,6\% contra 16,2\%. No Brasil, valor da opção hot-issue é maior em IPOs estabilizados: 3,5\% contra 1,2\% (Aggarwal (2000), não reporta dados sobre hot-issue nos EUA). No Brasil 
aparentemente não há diferença entre a sobrealocação como porcentagem da oferta total em IPOs estabilizados e não-estabilizados: 14,24\% contra 14,08\%. Nos EUA esta diferença é considerável: $20,3 \%$ contra $13,4 \%$. No geral, a sobrealocação nos EUA é maior que no Brasil: $17,1 \%$ contra $13,9 \%$. Isso pode estar refletindo o fato de que no Brasil existe o limite legal de $15 \%$ para a sobrealocação, enquanto que tal limite não existe nos EUA. Tanto no Brasil como nos EUA a opção greenshoe é mais intensamente usada em IPOs não-estabilizados que nos estabilizados: $13,5 \%$ contra 5,6\% no Brasil e 13,4\% contra 9,8\% nos EUA. No geral, o valor do greenshoe exercido nos EUA é ligeiramente maior que no Brasil: 11,5\% contra 9,2\%. Finalmente, pode-se observar que no Brasil a maneira como as emissões são alocados entre as diferentes classes de investidores aparentemente é a mesma entre IPOs estabilizados e não-estabilizados (Aggarwal (2000), não reporta esses dados para os EUA).

\section{Sobrealocação}

A Tabela 5 apresenta a análise dos determinantes da sobrealocação. Inicialmente pode-se observar que as variáveis relacionadas ao risco não apresentam qualquer significância estatística. Por outro lado, o Desvio-preço e todas as variáveis de demanda, (exceto o Lote-médio dos investidores institucionais nacionais) apresentam significância estatística. Os sinais também foram os esperados, i.e., Desvio-preço e Número-de-investidores apresentam efeito positivo sobre o exercício da sobrealocação. O mesmo ocorre com o Lote-médio, onde um maior lote recebido pelos investidores (sinal de fraca demanda) afeta negativamente a probabilidade de exercício completo da opção de sobrealocação. Estes resultados sugerem que o exercício da sobrealocação é determinado exclusivamente por fatores relacionados à demanda ex-ante. Estes resultados não corroboram as conjecturas de Prabhala e Puri (1998), Chowdhry e Nanda (1996) e Benveniste et alii (1996), pois se a estabilização está relacionada ao risco, a sobrealocação (a opção de estabilizar no momento seguinte) também deveria ser influenciada por ele. Por outro lado, este resultado também não corrobora Zhang (2004), pois segundo o mesmo a sobrealocação deveria ser negativamente correlacionada à demanda. 


\section{Tabela 4}

Comparação entre IPOs estabilizados e não-estabilizados no Brasil e nos EUA

Amostra compostas por empresas que abriram capital entre 2004 e 2007. Os dados dos Estados Unidos são referente a empresas que abriram o capital entre maio e julho de 1997 e provêm de Aggarwal (2000). Tamanho: montante distribuído em termos nominais em milhões de reais; Underprincing: retorno observado no primeiro dia de negociação em relação ao preço de distribuição; Hot-issue: número de ações exercidas pela opção em relação à emissão inicial; Sobrealocação: volume de ações exercidas pela opção de sobrealocação em relação à emissão inicial; Intensidade da estabilização: montante recomprado no mercado secundário durante o processo de estabilização; e Greenshoe: montante de ações adicionais adquiridas pelo underwriter junto ao emissor em relação ao número de ações oferecidas; Participação de investidores internacionais: proporção da oferta (acrescida da sobrealocação) alocada aos investidores internacionais; Participação de investidores institucionais nacionais: proporção da oferta (acrescida da sobrealocação) alocada aos investidores institucionais nacionais e Participação de investidores de varejo: proporção da oferta (acrescida da sobrealocação) alocada aos investidores de varejo

\begin{tabular}{l|c|c|c|c|c|c}
\hline & \multicolumn{2}{|c|}{ Brasil } & \multicolumn{3}{c}{ Estados Unidos } \\
\cline { 2 - 7 } & $\begin{array}{c}\text { Todos } \\
\text { IPOs }\end{array}$ & $\begin{array}{c}\text { IPOs } \\
\text { estabilizados }\end{array}$ & $\begin{array}{c}\text { IPOs } \\
\text { náo-estabilizados }\end{array}$ & Todos IPOs & $\begin{array}{c}\text { IPOs } \\
\text { estabilizados }\end{array}$ & $\begin{array}{c}\text { IPOs } \\
\text { ná-estabilizados }\end{array}$ \\
\hline $\begin{array}{l}\text { Número e IPOs } \\
\text { Montante } \\
\text { (US\$ milhões) }\end{array}$ & 384 & 275 & 512 & 96 & 82 & 113 \\
\hline Underpricing & $5,6 \%$ & $4,0 \%$ & $12,6 \%$ & $16,2 \%$ & $9,3 \%$ & $24,2 \%$ \\
\hline Hot issue & $2,3 \%$ & $1,2 \%$ & $3,5 \%$ & - & - & - \\
\hline $\begin{array}{l}\text { Sobrealocação } \\
\text { (em razão da emissão) }\end{array}$ & $13,9 \%$ & $14,24 \%$ & $14,08 \%$ & $17,1 \%$ & $20,3 \%$ & $13,4 \%$ \\
\hline $\begin{array}{l}\text { Intensidade da estabilização } \\
\text { (em razão da sobrealocação) }\end{array}$ & $34,4 \%$ & $62,5 \%$ & - & - & - & - \\
\hline $\begin{array}{l}\text { Intensidade da estabilizção } \\
\text { (em razão do valor da emissão) }\end{array}$ & $4,7 \%$ & $8,6 \%$ & - & - & $10,8 \%$ & - \\
\hline $\begin{array}{l}\text { Greenshoe } \\
\text { (em razão da sobrealocação) }\end{array}$ & $65.7 \%$ & $37,8 \%$ & $100 \%$ & - & - & - \\
\hline $\begin{array}{l}\text { Greenshoe } \\
\text { (em razão do valor da emissão) }\end{array}$ & $9,2 \%$ & $5,6 \%$ & $13,5 \%$ & $11,5 \%$ & $9,8 \%$ & $13,4 \%$ \\
\hline $\begin{array}{l}\text { Participação de } \\
\text { investidores internacionais }\end{array}$ & $69,9 \%$ & $67,64 \%$ & $65,94 \%$ & - & - & - \\
\hline $\begin{array}{l}\text { Participação de investidores } \\
\text { institucionais nacionais }\end{array}$ & $20 \%$ & $19,58 \%$ & $20,53 \%$ & - & - & - \\
\hline $\begin{array}{l}\text { Participação de investidores } \\
\text { de varejo }\end{array}$ & $9,9 \%$ & $10,09 \%$ & $9,82 \%$ & & & \\
\hline
\end{tabular}


Tabela 5

Análise do exercício da opção de sobrealocação

Análise do exercício da opção de sobrealocação estimada pelo seguinte modelo: sobrealocação $=\beta 1+\beta 2$ Tamanho $+\beta 3$ Comissão $+\beta 4$ Underwriter $+\beta 5$ Preço $+\beta 6$ Intervalo-de-preço $+\beta 7$ Desvio-preço $+\beta 8$ Lote-médio $+\beta 9$ Número-de-investidores. A variável dependente assume valor 1 se ocorreu exercício total da opcão de sobrealocação e 0 caso contrário. Os valores reportados referem-se aos efeitos marginais. As variáveis explicativas são: Tamanho: logaritmo do valor da oferta (excluídas a sobrealocação e a opção hot issue); Comissão: comissão percentual do underwriter; Underwriter: grau atribuído do underwriter participante da oferta de maior reputação segundo a escala desenvolvida por Carter e Manaster (1990) e atualizado por Jay Ritter para o período de 2001-2004; Preço: preço de distribuição; Intervalo-de-preço: diferença entre o valor máximo e mínimo do intervalo de preço previsto dividido pelo preço médio do intervalo; Desvio-preço: relação entre o preço estipulado e o valor médio do intervalo de preços previsto para a ação; Lote-médio: lote médio adquirido pelos investidores estrangeiros, institucionais nacionais e de varejo; Número: número de investidores estrangeiros, institucionais nacionais e de varejo participantes. Os estimadores foram obtidos usando a matriz de covariância robusta. Entre parênteses são apresentadas as estatísticas $t$. O coeficiente da constante foi omitido. Amostra formada por 98 IPOs

\begin{tabular}{|c|c|c|c|c|c|c|c|}
\hline & (1) & (2) & (3) & (4) & (5) & (6) & (7) \\
\hline Tamanho & $\begin{array}{l}-0,035 \\
(0,48)\end{array}$ & $\begin{array}{l}-0,054 \\
(0,83)\end{array}$ & $\begin{array}{l}-0,002 \\
(0,02)\end{array}$ & $\begin{array}{l}-0,078 \\
(1,27)\end{array}$ & $\begin{array}{l}-0,135 \\
(1,48)\end{array}$ & $\begin{array}{c}-0,108 \\
(1,44)\end{array}$ & $\begin{array}{l}-0,049 \\
(1,04)\end{array}$ \\
\hline Comissão & $\begin{array}{l}0,818 \\
(0,28)\end{array}$ & $\begin{array}{l}1,119 \\
(0,33)\end{array}$ & $\begin{array}{l}1,724 \\
(0,51)\end{array}$ & $\begin{array}{l}0,597 \\
(0,18)\end{array}$ & $\begin{array}{l}1,654 \\
(0,59)\end{array}$ & $\begin{array}{l}1,632 \\
(0,53)\end{array}$ & $\begin{array}{l}0,613 \\
(0,38)\end{array}$ \\
\hline Underwriter & $\begin{array}{l}0,025 \\
(1,09)\end{array}$ & $\begin{array}{l}0,038 \\
(1,40)\end{array}$ & $\begin{array}{l}0,027 \\
(1,06)\end{array}$ & $\begin{array}{l}0,033 \\
(1,36)\end{array}$ & $\begin{array}{l}0,026 \\
(1,20)\end{array}$ & $\begin{array}{l}0,033 \\
(1,52)\end{array}$ & $\begin{array}{l}0,011 \\
(1,01)\end{array}$ \\
\hline Preço & $\begin{array}{l}-0,007 \\
(1,39)\end{array}$ & $\begin{array}{l}-0,001 \\
(0,08)\end{array}$ & $\begin{array}{l}0,001 \\
(0,03)\end{array}$ & $\begin{array}{l}-0,002 \\
(0,48)\end{array}$ & $\begin{array}{l}-0,004 \\
(0,93)\end{array}$ & $\begin{array}{l}-0,004 \\
(0,81)\end{array}$ & $\begin{array}{l}-0,001 \\
(0,42)\end{array}$ \\
\hline Intervalo-de-preço & $\begin{array}{c}0,18 \\
(0,29)\end{array}$ & $\begin{array}{l}0,251 \\
(0,43)\end{array}$ & $\begin{array}{l}0,391 \\
(0,61)\end{array}$ & $\begin{array}{l}-0,37 \\
(0,59)\end{array}$ & $\begin{array}{c}0,23 \\
(0,42)\end{array}$ & $\begin{array}{l}0,717 \\
(1,13)\end{array}$ & $\begin{array}{l}-0,11 \\
(0,37)\end{array}$ \\
\hline Desvio-preço & $\begin{array}{c}0,723^{* * * *} \\
(2,84)\end{array}$ & & & & & & \\
\hline Lote-médio estrangeiros & & $\begin{array}{c}-15,49^{* * *} \\
(1,96)\end{array}$ & & & & & \\
\hline Lote-médio institucionais nacionais & & & $\begin{array}{l}-7,62 \\
(0,70)\end{array}$ & & & & \\
\hline Lote-médio varejo & & & & $\begin{array}{c}-4140 * * \\
(2,55)\end{array}$ & & & \\
\hline Número estrangeiros & & & & & $\begin{array}{c}0,0012^{* * *} \\
(1,97)\end{array}$ & & \\
\hline Número institucionais nacionais & & & & & & $\begin{array}{c}0,001 * * * \\
(2,90)\end{array}$ & \\
\hline Número varejo & & & & & & & $\begin{array}{c}0,00002^{* * * *} \\
(3,28)\end{array}$ \\
\hline Pseudo $R^{2}$ & 0,103 & 0,074 & 0,026 & 0,114 & 0,101 & 0,108 & 0,21 \\
\hline Wald $\chi^{2}$ & 11,02 & 6,38 & 3,07 & 8,16 & 8,62 & 10,93 & 12,56 \\
\hline Observ. corretas & $81,60 \%$ & $77,50 \%$ & $81,60 \%$ & $78,60 \%$ & $82,65 \%$ & $81,63 \%$ & $86,70 \%$ \\
\hline
\end{tabular}

\section{Ocorrência de Estabilização}

Preliminarmente discutimos a análise de diferenças de médias (Tabela 6). Essa análise sugere que a ocorrência de estabilização é positivamente afetada pelo risco: IPOs estabilizados são caracterizados por menor volume de emissão, menor preço de emissão e maior intervalo de preços, todos estatisticamente significantes ao nível de 5\%. Como essas variáveis são proxy para o risco, estes resultados suportam as conjecturas de Chowdhry e Nanda (1996) e Benveniste et alii (1996) (em detrimento a Prabhala e Puri (1998)), segundo os quais a estabilização é um substituto do underpricing e, portanto, um maior risco conduz a uma maior probabilidade de estabilização. Quanto às características de demanda, IPOs que sofrem estabilização normalmente são apreçados abaixo do ponto médio do faixa inicial 
de preços, conforme revela a variável Desvio-preço. Além disso, em IPOs estabilizados o número de investidores institucionais nacionais e estrangeiros é menor, ao passo que o lote-médio é maior, sendo que o mesmo padrão é observado para investidores de varejo, embora a diferença não seja estatisticamente significante. Em geral estes resultados indicam que os IPOs que recebem suporte de preço apresentam baixa demanda ex-ante. Finalmente, a qualidade dos underwriters, bem como a comissão cobrada pelos mesmos, parece não estar correlacionada à ocorrência de estabilização.

Tabela 6

Análise da ocorrência de estabilização - comparação de médias

Análise da diferença das médias das variáveis independentes, segmentando-as entre IPOs que receberam suporte de preços, ou seja, foram estabilizados e aqueles que não receberam. As variáveis são: Tamanho: logaritmo do valor da oferta (excluídas a sobrealocação e a opção hot issue); Comissão: comissão percentual do underwriter; Underwriter: grau atribuído do underwriter participante da oferta de maior reputação segundo a escala desenvolvida por Carter e Manaster (1990) e atualizado por Jay Ritter para o período de 2001-2004; Preço: preço estipulado para a venda da ação; Intervalo-de-preço: diferença entre o valor máximo e mínimo do intervalo de preço previsto dividido pelo preço médio do intervalo; Desvio-preço: relação entre o preço estipulado e o valor médio do intervalo de preços previsto para a ação; Lote-médio: lote médio adquirido pelos investidores estrangeiros, institucionais nacionais e de varejo; Número: número de investidores estrangeiros, institucionais nacionais e de varejo participantes. A amostra formada pelas 96 observações em que houve sobrealocação.

\begin{tabular}{|c|c|c|c|c|c|c|c|}
\hline & \multicolumn{2}{|c|}{ Todos os IPOs } & \multicolumn{2}{|c|}{ IPOs não estabilizados } & \multicolumn{2}{|c|}{ IPOs estabilizados } & \multirow[b]{2}{*}{$\begin{array}{l}\text { Dif. de médias } \\
\text { Estatística } t\end{array}$} \\
\hline & Média & \begin{tabular}{|l} 
Desvio \\
padrão
\end{tabular} & Média & $\begin{array}{l}\text { Desvio } \\
\text { padrão }\end{array}$ & Média & $\begin{array}{l}\text { Desvio } \\
\text { padrão }\end{array}$ & \\
\hline & \multicolumn{2}{|c|}{$\mathrm{N}=96$} & \multicolumn{2}{|c|}{$\mathrm{N}=43$} & \multicolumn{2}{|c|}{$\mathrm{N}=53$} & \\
\hline Tamanho & 20,13 & 0,553 & 20,3 & 0,688 & 20 & 0,37 & $2,56^{* * *}$ \\
\hline Comissão & 0,041 & 0,012 & 0,039 & 0,009 & 0,042 & 0,014 & 1,40 \\
\hline Underwriter & 8,49 & 1,404 & 8,4 & 1,697 & 8,72 & 0,489 & 1,19 \\
\hline Preço emissão & 19,41 & 8,374 & 21,89 & 8,393 & 17,62 & 7,927 & $2,53 * *$ \\
\hline Desvio preço médio & $-0,036$ & 0,162 & 0,031 & 0,141 & $-0,081$ & 0,155 & $3,73^{* * * *}$ \\
\hline Intervalo de preço & 0,243 & 0,065 & 0,223 & 0,077 & 0,258 & 0,049 & $2,57 * *$ \\
\hline Retorno ( $1^{\circ}$ dia) & 0,056 & 0,1 & 0,126 & 0,1 & 0,004 & 0,058 & 7,07 *** \\
\hline Retorno ajustado ( $1^{\circ}$ dia $)$ & 0,052 & 0,099 & 0,122 & 0,097 & 0,0003 & 0,059 & $7,18^{* * *}$ \\
\hline Lote-médio estrangeiros & 0,007 & 0,005 & 0,005 & 0,003 & 0,009 & 0,006 & $3,87^{* * *}$ \\
\hline Lote-médio institucionais nac. & 0,002 & 0,003 & 0,001 & 0,001 & 0,002 & 0,004 & $2,43^{* *}$ \\
\hline Lote-médio varejo & 0,00002 & 0,00003 & 0,00002 & 0,00002 & 0,00002 & 0,0004 & 1,17 \\
\hline Número estrangeiros & 150 & 157 & 214 & 213 & 103 & 59 & $3,28 * * *$ \\
\hline Número institucionais nac. & 169 & 129 & 234 & 147 & 122 & 82 & $4,43^{* * * *}$ \\
\hline Número varejo & 12616 & 26663 & 16712 & 39437 & 9704 & 6545 & 1,15 \\
\hline
\end{tabular}

***,**,* indicam significância estatística aos níveis de $1 \%, 5 \%$ e $10 \%$ respectivamente. 
A Tabela 7 apresenta a análise de regressão dos determinantes da ocorrência de estabilização. Como esperado, o volume da emissão (Tamanho) exerce efeito negativo e estatisticamente significante sobre a probabilidade de ocorrência de estabilização em quatro das sete regressões. A amplitude do intervalo de preços apresenta efeito positivo e significante em seis regressões. O coeficiente da variável Preço apresenta sinal negativo, porém apenas marginalmente significante. O coeficiente da variável Comissão, apesar do sinal positivo, não apresenta significância estatística em qualquer uma das regressões. Finalmente, a variável $U n$ derwriter apresenta sinal positivo com significância estatística a 10\% em quatro regressões. As variáveis Desvio-preço e Número-de-investidores apresentam coeficiente negativo e estatisticamente significante, exceto no caso dos investidores de varejo, ao passo que a variável Lote-médio apresenta significância apenas no caso dos investidores estrangeiros. Em geral estes resultados indicam que a probabilidade de ocorrência de estabilização está associada a alto risco, baixa demanda e à maior reputação dos underwriters. Os resultados sobre o efeito do risco são consistentes com Chowdhry e Nanda (1996) e Benveniste et alii (1996), contrários a Prabhala e Puri (1998). Os resultados com relação a demanda são consistentes com Zhang (2004). O resultado com relação à reputação do underwriter é coerente com Lewellen (2006). 
Tabela 7

Análise da ocorrência de estabilização

Análise da ocorrência de estabilização de preços estimada pelo seguinte modelo: ocorrência $=\beta 1+\beta 2$ Tamanho $+\beta 3$ Comissão $+\beta 4$ Underwriter $+\beta 5$ Preço $+\beta 6$ Intervalo-de-preço $+\beta 7$ Desvio-preço $+\beta 8$ Lote-médio $+\beta 9$ Número. A variável dependente assume valor 1 se ocorreu estabilização de preços e 0 caso contrário. Os valores reportados referem-se aos efeitos marginais. As variáveis explicativas são: Tamanho: logaritmo do valor da oferta (excluídas a sobrealocação e a opção hot issue); Comissão: comissão percentual do underwriter; Underwriter: grau atribuído do underwriter participante da oferta de maior reputação segundo a escala desenvolvida por Carter e Manaster (1990) e atualizado por Jay Ritter para o período de 2001-2004; Preço: preço estipulado para a venda da ação; Intervalo-de-preço: diferença entre o valor máximo e mínimo do intervalo de preço previsto dividido pelo preço médio do intervalo; Desvio-preço: relação entre o preço estipulado e o valor médio do intervalo de preços previsto para a ação; Lote-médio: lote médio adquirido pelos investidores estrangeiros, institucionais nacionais e de varejo; Número: número de investidores estrangeiros, institucionais nacionais e de varejo participantes. Os estimadores foram obtidos usando a matriz de covariância robusta. Estatísticas $t$ aparecem em parênteses. O coeficiente da constante foi omitido. A amostra formada por 96 IPOs em que houve sobrealocação

\begin{tabular}{|c|c|c|c|c|c|c|c|}
\hline & (1) & (2) & (3) & (4) & (5) & (6) & (7) \\
\hline Tamanho & $\begin{array}{c}-0,291 * * \\
(2,24)\end{array}$ & $\begin{array}{l}-0,182 \\
(1,49)\end{array}$ & $\begin{array}{c}-0,225^{*} \\
(1,86)\end{array}$ & $\begin{array}{c}-0,288^{* * *} \\
(2,33)\end{array}$ & $\begin{array}{l}-0,144 \\
(0,96)\end{array}$ & $\begin{array}{l}-0,182 \\
(1,25)\end{array}$ & $\begin{array}{c}-0,321^{* *} \\
(2,40)\end{array}$ \\
\hline Comissão & $\begin{array}{l}3,587 \\
(0,71)\end{array}$ & $\begin{array}{l}1,734 \\
(0,36)\end{array}$ & $\begin{array}{l}1,004 \\
(0,22)\end{array}$ & $\begin{array}{l}0,524 \\
(0,12)\end{array}$ & $\begin{array}{l}1,578 \\
(0,34)\end{array}$ & $\begin{array}{l}2,097 \\
(0,47)\end{array}$ & $\begin{array}{l}0,257 \\
(0,06)\end{array}$ \\
\hline Underwriter & $\begin{array}{c}0,083^{*} \\
(1,70)\end{array}$ & $\begin{array}{c}0,07 \\
(1,53) \\
\end{array}$ & $\begin{array}{l}0,066 \\
(1,52)\end{array}$ & $\begin{array}{l}0,081^{*} \\
(1,86)\end{array}$ & $\begin{array}{l}0,079^{*} \\
(1,73)\end{array}$ & $\begin{array}{l}0,076 \\
(1,57)\end{array}$ & $\begin{array}{l}0,086^{*} \\
(1,96)\end{array}$ \\
\hline Preço & $\begin{array}{l}-0,002 \\
(0,31)\end{array}$ & $\begin{array}{l}-0,011 \\
(1,55)\end{array}$ & $\begin{array}{c}-0,013^{*} \\
(1,68)\end{array}$ & $\begin{array}{c}-0,01 \\
(1,36)\end{array}$ & $\begin{array}{l}-0,006 \\
(0,81)\end{array}$ & $\begin{array}{l}-0,007 \\
(1,06)\end{array}$ & $\begin{array}{l}-0,011 \\
(1,47)\end{array}$ \\
\hline Intervalo-de-preço & $\begin{array}{c}2,135^{* * *} \\
(2,47)\end{array}$ & $\begin{array}{c}1,853^{* * *} \\
(2,06)\end{array}$ & $\begin{array}{l}1,609^{*} \\
(1,90)\end{array}$ & $\begin{array}{c}1,990 * * \\
(2,06)\end{array}$ & $\begin{array}{c}2,026^{* * *} \\
(2,24)\end{array}$ & $\begin{array}{l}1,085 \\
(1,19)\end{array}$ & $\begin{array}{l}1,739^{*} \\
(1,88)\end{array}$ \\
\hline Desvio-preço & $\begin{array}{c}-1,346^{\text {*** }} \\
(3,06)\end{array}$ & & & & & & \\
\hline Lote-médio estrangeiros & & $\begin{array}{c}43,44^{* * * *} \\
(3,42)\end{array}$ & & & & & \\
\hline Lote-médio institucionais nacionais & & & $\begin{array}{l}102,98 \\
(1,61)\end{array}$ & & & & \\
\hline Lote-médio varejo & & & & $\begin{array}{c}2288 \\
(1,15)\end{array}$ & & & \\
\hline $\begin{array}{l}\text { Número } \\
\text { estrangeiros }\end{array}$ & & & & & $\begin{array}{c}-0,0025^{* * * *} \\
(2,90)\end{array}$ & & \\
\hline Número institucionais nacionais & & & & & & $\begin{array}{c}-0,0018^{* * *} \\
(2,82)\end{array}$ & \\
\hline Número varejo & & & & & & & $\begin{array}{c}-0,000002 \\
(0,12)\end{array}$ \\
\hline Pseudo $R^{2}$ & 0,215 & 0,221 & 0,201 & 0,153 & 0,219 & 0,207 & 0,146 \\
\hline Wald $\chi^{2}$ & 31,3 & 28,8 & 25,8 & 24 & 21,9 & 23 & 22,9 \\
\hline Observ. corretas & $68,7 \%$ & $64,6 \%$ & $64,6 \%$ & $66,7 \%$ & $70,8 \%$ & $70,8 \%$ & $66,7 \%$ \\
\hline
\end{tabular}

***,**,* indicam significância estatística aos níveis de $1 \%, 5 \%$ e $10 \%$ respectivamente.

\section{Intensidade da Estabilização (ASC)}

Finalmente a Tabela 8 apresenta os determinantes da intensidade da estabilização. No que concerne ao sinal das variáveis explicativas, os resultados são semelhantes aos encontrados na análise dos determinantes da ocorrência da estabilização, porém existem diferenças no que concerne à significância estatística. As variáveis Tamanho, Comissão, Underwriter e Intervalo-de-preço não apresentaram significância estatística. $\mathrm{O}$ preço apresenta sinal negativo, tal como na análise da probabilidade, sendo estatisticamente significante em cinco das sete regressões. 
Tabela 8

Intensidade da estabilização

Regressão tobit baseada no seguinte modelo: Intensidade de Estabilização $=\beta 1+\beta 2$ Tamanho $+\beta 3$ Comissão $+\beta 4$ Underwriter $+\beta 5$ Preço $+\beta 6$ Intervalo-de-preço $+\beta 7$ Desvio-preço $+\beta 8$ Lote-médio $+\beta 9$ Número. A variável dependente é definida pela razão entre ações recompradas durante a estabilização e a sobrealocação. As variáveis independentes são: Tamanho: logaritmo do valor da oferta (excluídas a sobrealocação e a opção hot issue); Comissão: comissão percentual do underwriter; Underwriter: grau atribuído do underwriter participante da oferta de maior reputação segundo a escala desenvolvida por Carter e Manaster (1990) e atualizado por Jay Ritter para o período de 2001-2004; Preço: preço estipulado para a venda da ação; Intervalo-de-preço: diferença entre o valor máximo e mínimo do intervalo de preço previsto dividido pelo preço médio do intervalo; Desviopreço: relação entre o preço estipulado e o valor médio do intervalo de precos previsto para a ação; Lote-médio: lote médio adquirido pelos investidores estrangeiros, institucionais nacionais e de varejo; Número: número de investidores estrangeiros, institucionais nacionais e de varejo participantes. Os estimadores foram obtidos usando a matriz de covariância robusta. Entre parênteses são apresentadas as estatísticas $t$. O coeficiente da constante foi omitido. A amostra formada por 96 IPOs em que houve sobrealocação

\begin{tabular}{|c|c|c|c|c|c|c|c|}
\hline & (1) & $(2)$ & (3) & (4) & (5) & (6) & (7) \\
\hline Tamanho & $\begin{array}{c}-0,136^{* * *} \\
(0,55)\end{array}$ & $\begin{array}{l}-0,053 \\
(0,25)\end{array}$ & $\begin{array}{c}-0,192^{*} \\
(0,79)\end{array}$ & $\begin{array}{c}-0,301 * * \\
(0,84)\end{array}$ & $\begin{array}{l}-0,199 \\
(0,60)\end{array}$ & $\begin{array}{l}-0,064 \\
(0,25)\end{array}$ & $\begin{array}{l}-0,260 \\
(0,91)\end{array}$ \\
\hline Comissão & $\begin{array}{l}16,99 \\
(1,21)\end{array}$ & $\begin{array}{l}14,81 \\
(1,08)\end{array}$ & $\begin{array}{c}13,71 \\
(1,02)\end{array}$ & $\begin{array}{l}11,60 \\
(0,86)\end{array}$ & $\begin{array}{l}12,89 \\
(1,29)\end{array}$ & $\begin{array}{c}13,77 \\
(1,20)\end{array}$ & $\begin{array}{l}11,54 \\
(0,73)\end{array}$ \\
\hline Underwriter & $\begin{array}{l}0,161 \\
(1,21)\end{array}$ & $\begin{array}{l}0,119 \\
(0,95)\end{array}$ & $\begin{array}{l}0,135 \\
(1,00)\end{array}$ & $\begin{array}{l}0,167 \\
(0,70)\end{array}$ & $\begin{array}{l}0,151 \\
(1,14)\end{array}$ & $\begin{array}{l}0,145 \\
(0,99)\end{array}$ & $\begin{array}{l}0,168 \\
(0,86)\end{array}$ \\
\hline Preço & $\begin{array}{l}-0,017 \\
(0,84)\end{array}$ & $\begin{array}{c}-0,039^{* * *} \\
(2,16)\end{array}$ & $\begin{array}{c}-0,045^{*} \\
(3,16)\end{array}$ & $\begin{array}{c}-0,034^{*} \\
(1,69)\end{array}$ & $\begin{array}{l}-0,023 \\
(1,41)\end{array}$ & $\begin{array}{c}-0,031^{* * *} \\
(2,25)\end{array}$ & $\begin{array}{c}-0,035^{*} \\
(1,87)\end{array}$ \\
\hline Intervalo-de-preço & $\begin{array}{c}2,874 * * \\
(1,17)\end{array}$ & $\begin{array}{c}2,58 \\
(1,22)\end{array}$ & $\begin{array}{l}2,295 \\
(1,06)\end{array}$ & $\begin{array}{l}2,700 \\
(1,00)\end{array}$ & $\begin{array}{c}2,8174 \\
(1,28)\end{array}$ & $\begin{array}{l}1,734 \\
(0,99)\end{array}$ & $\begin{array}{l}2,533 \\
(0,99)\end{array}$ \\
\hline Desvio-preço & $\begin{array}{c}-2,341 \text { *** } \\
(2,37)\end{array}$ & & & & & & \\
\hline Lote-médio estrangeiros & & $\begin{array}{c}55,63^{* * *} \\
(2,07)\end{array}$ & & & & & \\
\hline Lote-médio institucionais nacionais & & & $\begin{array}{l}61,48 \\
(0,72)\end{array}$ & & & & \\
\hline Lote-médio varejo & & & & $\begin{array}{c}488 \\
(0,64)\end{array}$ & & & \\
\hline Número estrangeiros & & & & & $\begin{array}{c}-0,006^{* * *} \\
(2,88)\end{array}$ & & \\
\hline Número institucionais nacionais & & & & & & $\begin{array}{c}-0,002^{*} \\
(1,73)\end{array}$ & \\
\hline Número varejo & & & & & & & $\begin{array}{c}-0,000002 \\
(0,19)\end{array}$ \\
\hline Pseudo $R^{2}$ & 0,127 & 0,117 & 0,102 & 0,086 & 0,151 & 0,101 & 0,086 \\
\hline Wald $\chi^{2}$ & 13,87 & 11,88 & 19,19 & 11,62 & 20,20 & 20,80 & 15,99 \\
\hline
\end{tabular}

***,**,* indicam significância estatística aos níveis de $1 \%, 5 \%$ e $10 \%$ respectivamente.

As variáveis de demanda dos investidores estrangeiros e institucionais nacionais apresentam significância estatística. Nota-se que a participação de investidores de varejo não é relevante na determinação da intensidade da estabilização, tal como visto na probabilidade de ocorrência de estabilização. Isto possivelmente decorre da reduzida variação longitudinal da participação do varejo nas emissões, pois normalmente a sua alocação é próxima ao mínimo de $10 \%$ estabelecido pela Bovespa para emissões que ocorrem nos segmentos diferenciados de Governança Corporativa. A variável Desvio-preço apresentou coeficiente negativo e significante, sugerindo que revisões positivas de preço durante o bookbuilding revelam, ainda que parcialmente, um excesso de demanda (Hanley et alii, 1993) e consequente reduzida necessidade de estabilização.

Finalmente a reputação do underwriter não apresenta significância estatística em qualquer das regressões. Isto sugere que a reputação do underwriter é impor- 
tante para prever se este faz estabilização, mas não para prever a intensidade com que este estabiliza.

Os nossos resultados indicam que os IPOs com maior risco ex-ante são mais intensamente estabilizados, contrariando Prabhala e Puri (1998) e corroborando Chowdhry e Nanda (1996) e Benveniste et alii (1996). Que a reputação do underwriter é importante para determinar se os IPOs são estabilizados, mas não para determinar a intensidade da estabilização. Finalmente, corroborando Zhang (2004) os IPOs estabilizados são aqueles com menor demanda. Em geral, nenhum dos modelos formais de estabilização explica satisfatoriamente o processo de estabilização.

\section{Conclusão}

A literatura empírica sobre a estabilização de preço em IPOs é relativamente limitada e fragmentada. Em grande parte isso se deve à reduzida disponibilidade de dados, uma vez que nos Estados Unidos e em vários outros países, os underwriters não são obrigados a divulgar informações sobre a estabilização. À exceção de Aggarwal (2000), os demais estudos usam estabilização presumida, i.e., algum modelo é usado para prever a ocorrência de estabilização. Este procedimento, além de apresentar os problemas associados ao erros de medida, torna difícil distinguir a ocorrência de estabilização de sua intensidade. Além do mais, não se dispõe de informação sobre a demanda revelada durante o processo de bookbuilding nem sobre o montante sobrealocado.

No Brasil, desde 2003, a CVM determina que, após o encerramento da estabilização, o underwriter publique detalhes sobre como a emissão foi distribuída entre os diversos grupos de investidores, a sobrealocação, a cobertura por meio de recompras no mercado secundário e o exercício do greenshoe. Esta disponibilidade de informação permite uma análise mais precisa dos determinantes da estabilização em três aspectos distintos: sobrealocação, ocorrência de estabilização (recompras no mercado secundário) e intensidade da estabilização (razão entre recompras e sobrealocação).

Nossas estatísticas mostram que 1) a estabilização de preços é um aspecto importante da abertura de capital no Brasil: quase todos os IPOs preveem a estabilização de preço (apenas 2 IPOs não o fizeram). A sobrealocação média é de 13,9\% em relação à oferta inicial. Em apenas 17 IPOs, a sobrealocação foi menor do que $15 \%$ e em somente 2 casos não houve sobrealocação. O ASC foi praticado em 53 dos 96 IPOs com sobrealocação $(55,2 \%)$. Em média 34,4\% da sobrealocação (4,7\% do montante ofertado) foram recomprados e 2) os dados para estabilização no Brasil são semelhantes aos dos EUA. A nossa análise empírica indica que: 1) os diferentes aspectos da estabilização possuem determinantes distintos; 2) alta demanda é o único fator que explica o exercício da opção de sobrealocação; 3) os IPOs estabilizados são aqueles de menor volume financeiro; com maior risco inicial de preço; conduzidos por underwriters de melhor reputação e que apresentam menor demanda da parte de investidores institucionais nacionais e es- 
trangeiros; 4) a intensidade da estabilização é negativamente correlacionada com a demanda de investidores estrangeiros e institucionais domésticos; 5) o preço apresenta correlação negativa tanto com a probabilidade quanto com a intensidade da estabilização, ao passo que a amplitude do intervalo de preços constante do prospecto apresenta correlação positiva e significante estatisticamente apenas para a probabilidade de ocorrência de estabilização e 6) a reputação do underwriter não apresenta significância estatística sobre a intensidade da estabilização sugerindo que a reputação do underwriter é importante para prever se este a faz, mas não para a intensidade com que a faz.

$\mathrm{O}$ fato de que os diferentes aspectos da estabilização possuem diferentes determinantes indica que nenhum dos modelos teóricos considerados (Chowdhry e Nanda, 1996, Benveniste et alii, 1996, Prabhala e Puri, 1998, Zhang, 2004), explicam amplamente este processo. O fato de que IPOs com maior risco ex-ante são mais frequentemente e intensamente estabilizados corroboram Chowdhry e Nanda (1996) e Benveniste et alii (1996) e contradizem Prabhala e Puri (1998). O fato de que a ocorrência e intensidade da estabilização dos IPOs está relacionada a baixa demanda estão em linha com o modelo de Zhang (2004). Nenhuma das teorias discutidas explica o fato de a sobrealocação estar positivamente e fundamentalmente relacionada a alta demanda pelo IPO. Nossas conclusões mostram a necessidade de estudos futuros que possibilitem uma melhor compreensão do processo de estabilização.

\section{Referências}

Aggarwal, R. (2000). Stabilization activities by underwriters after initial public offerings. Journal of Finance, 55:1075-1103.

Benveniste, L. M., Busaba, W. Y., \& Wilhelm Jr., W. J. (1996). Price stabilization as a bonding mechanism in new equity issues. Journal of Financial Economics, 42:223-255.

Benveniste, L. M., Erdal, S. M., \& Wilhelm Jr., W. J. (1998). Who benefits from secondary market price stabilization of IOPs? Journal of Banking \& Finance, 22:741-767.

Benveniste, L. M. \& Spindt, P. A. (1989). How investment banks determined price and allocation of new issues. Journal of Financial Economics, 24:213-232.

Boehmer, E. \& Fishe, R. P. H. (2004). Underwriter short covering in the IPO aftermarket: A clinical study. Journal of Corporate Finance, 10:575-594.

Carter, R. \& Manaster, S. (1990). Initial public offerings and underwriter reputation. Journal of Finance, 45:1045-1067.

Chen, H.-C. \& Ritter, J. (2000). The seven percent solution. Journal of Finance, 55:1105-1131. 
Chowdhry, B. \& Nanda, V. (1996). Stabilization, syndication, and pricing of IPOs. Journal of Financial and Quantitative Analysis, 31:25-42.

Chung, R., Lawrence, K., \& Rakita, I. (2000). The relationship between overallotment options, underwriting fees and price stabilization for canadian IPOs. Multinational Finance Journal, 4:5-34.

Edwards, A. K. \& Hanley, K. W. (2007). Short selling and failures to deliver in initial public offerings. Journal of Financial Economics, forthcoming. Disponível em: http://papers.ssrn.com/sol3/papers.cfm?abstract_ id=981242. Acesso em 19.09.2007.

Hanley, K. W., Kumar, A. A., \& Seguin, P. J. (1993). Price stabilization in the market for new issues. Journal of Financial Economics, 34:177-197.

Lee, C. M. C. \& Ready, M. J. (1991). Inferring trade direction from intraday data. Journal of Finance, 46:733-746.

Lewellen, K. (2006). Risk, reputation, and IPO price support. Journal of Finance, 61:613-653.

Ljungqvist, A. P., Jenkinson, T., \& Wilhelm Jr., W. J. (2003). Global integration of primary equity markets: The role of U.S. banks and U.S. investors. Review of Financial Studies, 16:63-99.

Muscarella, C. J., Peavy III, J. W., \& Vetsuypens, M. R. (1992). Optimal exercise of the over-allotment option in IPOs. Financial Analysts Journal, 38:76-80.

Prabhala, N. R. \& Puri, M. (1998). How does underwriter price support affect IPOs? Empirical evidence. Disponível em: http://papers.ssrn.com/ sol3/papers. cfm?abstract_id=95948. Acesso em 14.09.2007.

Rock, K. (1986). Why new issues are underpriced? Journal of Financial Economics, 15:187-212.

Ruud, J. S. (1993). Underwriter price support and the IPO underpricing puzzle. Journal of Financial Economics, 34:135-151.

Schultz, P. \& Zaman, M. A. (1994). Aftermarket support and underpricing of initial public offerings. Journal of Financial Economics, 35:199-219.

Tinic, S. M. (1988). Anatomy of initial public offerings of common stock. Journal of Finance, 43:789-822.

Wilhelm Jr., W. J. (1999). Secondary market stabilization of IPOs. Journal of Applied Corporate Finance, 12:78-85.

Zhang, D. (2004). Why do IPO underwriters allocate extra shares when they expect to buy them back? Journal of Financial and Quantitative Analysis, 39:571-594. 